\title{
Associative Long-Term Potentiation in Piriform Cortex Slices Requires GABA Blockade $^{2}$
}

\author{
Evan D. Kanter' and Lewis B. Haberly ${ }^{1.2}$ \\ 'Neuroscience Training Program and 'Department of Anatomy, University of Wisconsin, Madison, Wisconsin 53706
}

\begin{abstract}
Previous studies have demonstrated that NMDA-dependent, long-term potentiation (LTP) can be induced in both afferent and intrinsic association fiber systems in the piriform (primary olfactory) cortex. In this report we demonstrate that an associative form of LTP can be induced by coactivation of these two systems, which terminate on adjacent apical dendritic segments of pyramidal cells. Potentiating stimulus trains were delivered to either afferent or association fibers, and weak shocks, which were nonpotentiating when delivered alone, were delivered to the other pathway. Under control recording conditions where homosynaptic (single pathway) LTP is consistently evoked, coincident application of these stimuli falled to induce LTP of the weak shock response. However, after local blockade of the fast, GABA -mediated $^{-}$ IPSP, associative LTP was consistently produced in both directions. Induction was blocked by 0-2-amino-5-phosphonovaleric acid, indicating that it is dependent on activation of NMDA receptors. It is speculated that afferent and association fibers are segregated on different dendritic segments of pyramidal cells in piriform cortex to allow regulation of associative LTP by way of centrifugal inputs that modulate the activity of GABAergic interneurons.
\end{abstract}

[Key words: olfactory cortex, plasticity, inhibition, longterm potentiation, GABA, NMDA]

Piriform cortex has several features that make it a particularly attractive system for modeling associative, content addressable memory (Haberly, 1985; Haberly and Bower, 1989). These include a highly distributed input, highly interconnected principal cells, distributed positive feedback, and a spatially diffuse ensemble code. Pyramidal neurons in piriform cortex receive two excitatory inputs on adjacent segments of their apical dendrites: afferent fibers from the lateral olfactory tract (LOT) synapse distally in layer Ia, and intrinsic association fibers synapse more proximally in layer Ib (Price, 1973). This anatomical configuration, with distributed input (layer Ia) and distributed positive feedback (layer Ib) exciting adjacent dendritic segments, suggests the possibility of associative interactions based on coincident inputs from the two fiber systems. Associative synaptic plasticity between the two pathways could contribute to the discriminative

\footnotetext{
Received June 9, 1992; revised Dec. 8, 1992; accepted Dec. 10, 1992.

This work was supported by Grant NS19865 from the NINDS (L.B.H.) and NIH Training Grant GMO7507 (E.D.K.).

Correspondence should be addressed to Lewis B. Haberly, Department of Anatomy, University of Wisconsin, 1300 University Avenue, West Loading Dock, Madison, WI 53706.

Copyright (c) 1993 Society for Neuroscience $0270-6474 / 93 / 132477-06 \$ 05.00 / 0$
}

ability of this system (Wilson and Bower, 1988; Ambros-Ingerson et al., 1990; Ketchum and Haberly, 1991).

Long-term potentiation (LTP) is a form of activity-dependent synaptic plasticity that has been studied intensively in the hippocampal cortex as a model for a cellular mechanism of learning and memory (Bliss and Lynch, 1988; Madison et al., 1991). The commonly studied NMDA-dependent LTP is a long-lasting and synapse-specific enhancement of synaptic responses induced by brief high-frequency stimulation of excitatory pathways. The possible relationship of LTP to associative memory is perhaps best suggested by the particular form of LTP known as associative LTP. In the associative LTP paradigm, a weak (nonpotentiating) stimulus to one set of synaptic inputs can produce potentiation if paired with a strong (potentiating) stimulus to a second, independent set of synaptic inputs (Levy and Steward, 1979; Barrionuevo and Brown, 1983). The strong stimulus produces the critical level of postsynaptic depolarization necessary for LTP induction, which the weak stimulus alone is unable to generate. The weak stimulus does not need to be tetanic; it can be a single volley (Gustafsson and Wigström, 1986).

NMDA-dependent LTP in both afferent and association fiber pathways of piriform cortex has previously been described (Jung et al., 1990; Kanter and Haberly, 1990). This report demonstrates associative LTP between the two fiber pathways, which can be induced only after $\mathrm{GABA}_{\mathrm{A}}$ blockade.

A preliminary report of these results has becn published previously in abstract form (Kanter and Haberly, 1991).

\section{Materials and Methods}

Rats weighing approximately $200 \mathrm{gm}$ were decapitated under ether anesthesia. A block of brain containing piriform cortex was removed and slices $500 \mu \mathrm{m}$ thick were cut perpendicular to the cortical surface with a Vibratome (Lancer) in oxygen-saturated medium at $0^{\circ} \mathrm{C}$. Slices were allowed to recover for $2 \mathrm{hr}$ at room temperature before recording. The medium was $124 \mathrm{~mm} \mathrm{NaCl}, 5.0 \mathrm{~mm} \mathrm{KCl}, 2.4 \mathrm{mM} \mathrm{CaCl}_{2}, 1.3 \mathrm{mM} \mathrm{MgSO}_{4}$, $26 \mathrm{~mm} \mathrm{NaHCO}_{3}, 1.2 \mathrm{mM} \mathrm{KH}_{2} \mathrm{PO}_{4}$, and $10 \mathrm{~mm}$ D-glucose, equilibrated with $95 \% \mathrm{O}_{2}, 5 \% \mathrm{CO}_{2}$.

Recordings were taken from submerged slices continuously perfused with oxygenated medium at $30^{\circ} \mathrm{C}$ in the chamber described by Tseng and Haberly (1988). Extracellular field potentials were recorded using glass microelectrodes broken to tip diameters of $1-3 \mu \mathrm{m}$ and filled with $2 \mathrm{M} \mathrm{NaCl}$. Stimulus trains and test pulses were delivered through bipolar tungsten microelectrodes placed under direct vision in the lateral olfactory tract (LOT) for stimulation of afferent fibers and in layer Ib for stimulation of association fibers.

Test pulses were $100 \mu \mathrm{sec}$ shocks given at intervals of $10 \mathrm{sec}$ for LOT stimulation and 20-30 sec for layer Ib stimulation. The slower rate for layer Ib was required to maintain a stable response amplitude in this fiber system (Kanter and Haberly, 1990). Shock strength for test pulses was adjusted to give a response amplitude of approximately $1 \mathrm{mV}$ for layer Ia and $2 \mathrm{mV}$ for layer Ib (typically $30-50 \%$ of maximum). Pulses eliciting near-maximal responses were used for potentiating trains. Po- 


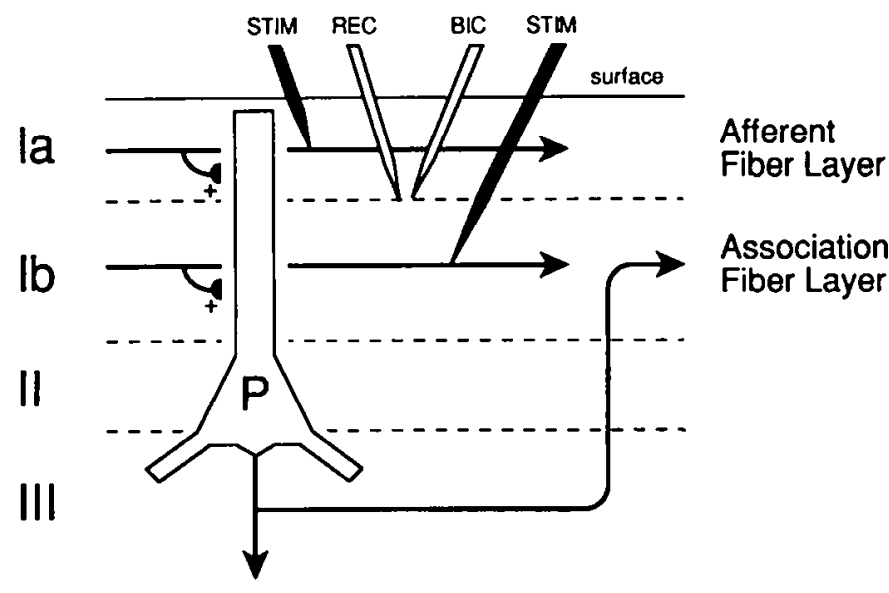

Figure 1. Schematic diagram of recording configuration. $P$, superficial pyramidal cell; plus signs indicate excitatory synapses; Roman numerals denote cortical layers; $B I C$, bicuculline-containing pipette.

tentiating trains consisted of 10 sets of four pulses at $100 \mathrm{~Hz}$ delivered at $200 \mathrm{msec}$ intervals. The $200 \mathrm{msec}$ interval approximates the rate of exploratory sniffing in the rat, which corresponds to the limbic theta rhythm (Macrides et al., 1982). This stimulus paradigm is highly effective for inducing LTP (Larson et al., 1986). During pairings of strong and weak stimuli, weak shocks (equivalent to test pulses) were delivered at 200 msec intervals between the second and third pulses of the fourpulse bursts. Amplified responses were digitized and stored by computer; calculation of the slope of the rising phase was automated.

In experiments where 2-5 $\mu \mathrm{M}$ bicuculline methiodide was bath applied, $\mathrm{Ca}^{2+}$ was elevated to $10 \mathrm{~mm}$ to block polysynaptic activity, and $\mathrm{KH}_{2} \mathrm{PO}$, was eliminated to prevent precipitation. In experiments using standard medium, $5 \mathrm{~mm}$ bicuculline was focally applied either from the recording pipette or from a second pipette inserted near the recording site. Bicuculline-containing pipettes were broken to tip diameters of $10-$ $20 \mu \mathrm{m}$, and when necessary, positive iontophoretic currents up to 20 nA were used to pass bicuculline. D-2-Amino-5-phosphonovaleric acid (D-APV), 3-amino-2-(4-chlorophenyl)-propylphosphonic acid (phaclofen), and 3-amino-2-(4-chlorophenyl)-2-hydroxy-propylsulfonic acid (2hydroxysaclofen) were bath applied. Bicuculline was from Sigma; D-APV was from Cambridge Research Biochemicals; phaclofen and 2-hydroxysaclofen were from Research Biochemicals, Inc.

\section{Results}

A schematic diagram of the recording configuration is shown in Figure 1. Afferent fiber synapses in layer Ia were activated by the stimulating electrode in the LOT. Association fiber synapses were activated by the stimulating electrode in the middle to decp part of layer Ib. The recording electrode near the layer $\mathrm{Ia} / \mathrm{Ib}$ border registered the active part of the dipole for association fibers and the passive part of the dipole for afferents, resulting in afferent and association fiber responses of opposite polarity.

Potentiating (strong) stimuli were delivered to cither afferents or association fibers and single (weak) pulses were delivered to the other pathway. Two controls were necessary in order to clearly establish that the LTP induced was associative in nature. A potentiating train to the strong pathway alone should not induce LTP in the weak pathway. Ten test pulses to the weak pathway at $200 \mathrm{msec}$ intervals should also have no effect.

Under the same conditions in which homosynaptic (single pathway) LTP can be consistently evoked (Kanter and Haberly, 1990), associative LTP could not be induced by pairing strong and weak stimuli. Occasionally, a small, brief potentiation of the association fiber response was seen (as in Fig. $3 B$ ), although in most cases this was not present. Paired stimulation in normal medium never produced any measurable effect on the afferent fiber response. Strong inhibitory mechanisms are present in piriform cortex, as in other types of cortex (Scholfield, 1973; Satou et al., 1982; Tseng and Haberly, 1988). Since GABA antagonists can facilitate LTP in the hippocampus (Wigström and Gustafsson, 1983, 1985; Gustafsson and Wigström, 1986), it was thought that blockade of inhibition with bicuculline, which blocks the fast, $\mathrm{Cl}^{-}$-mediated IPSP in piriform cortex, might enable induction of associative LTP in this system.

Two methods were used to introduce bicuculline. In initial experiments ( 10 slices) bicuculline $(2-5 \mu \mathrm{M})$ was bath applied. In normal bathing medium, this resulted in epileptiform bursting activity, characterized by large all-or-none responses having a distinct threshold. In order to prevent epileptiform responses, it was necessary to block polysynaptic transmission, an accept-
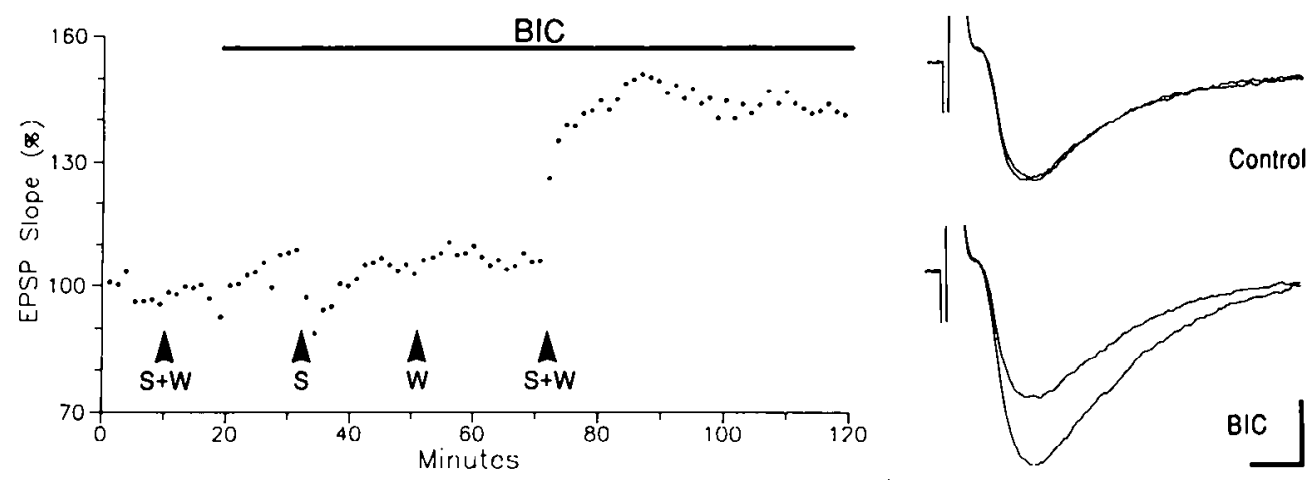

Figure 2. Associative LTP induction after bath application of bicuculline with elevated calcium. Potentiation of association fiber response by burst stimulation of afferent fibers is plotted as a function of time; amplitude is expressed as slope of rising phase of field EPSP; baseline response is normalized to $100 \%$. Bar denotes period of bath application of bicuculline $(B I C)$. $S$, strong potentiating trains to afferent fibers alone; $W$, weak shocks to association fibers alone; $S+W$, paired stimulation. Test pulses were delivered every 30 sec; each point is an average of four consecutive responses. Extracellular calcium was elevated to $10 \mathrm{~mm}$ to prevent epileptiform activity induced by bath-applied bicuculline. Superimposed field potential responses are shown at right, $5 \mathrm{~min}$ before and $20 \mathrm{~min}$ after paired stimulation for control condition (before application of bicuculline; top traces) and in the presence of bicuculline (bottom traces). Each trace is an average of six consecutive responses. Shock artifacts are truncated. Calibration: $2 \mathrm{msec}, 1 \mathrm{mV}$. 
A

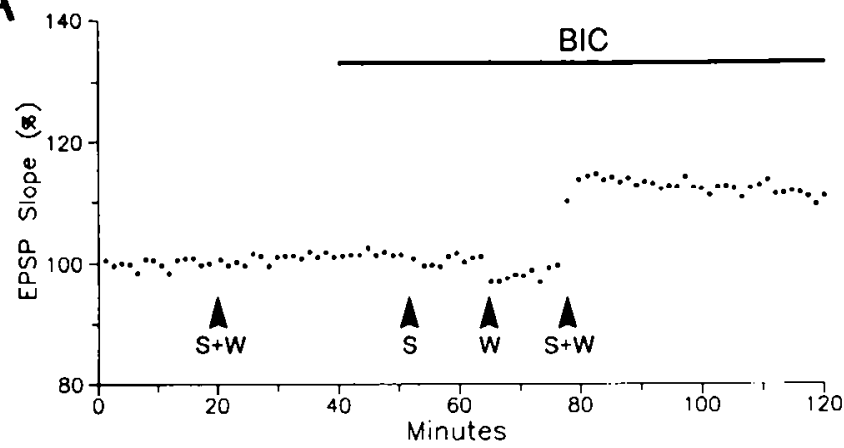

B

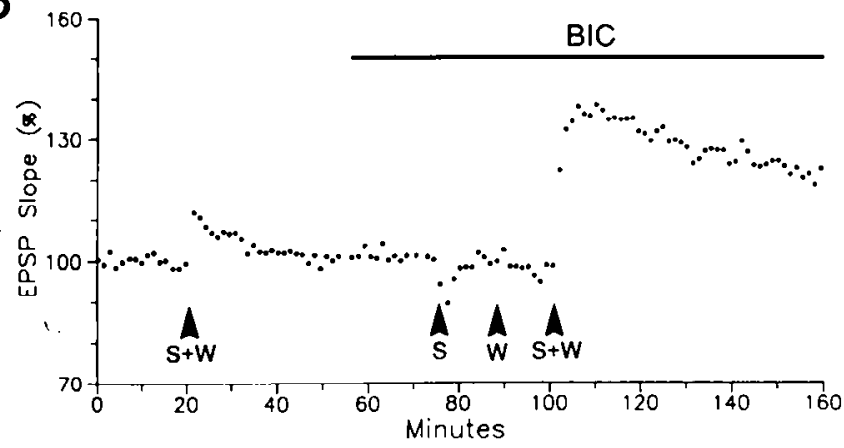

able approach since associative LTP induction in this paradigm requires only monosynaptic activation of $\mathrm{Ia}$ and $\mathrm{Ib}$ fibers. This was done by using a high concentration of $\mathrm{Ca}^{2+}$ in the medium, which elevates threshold without interfering with synaptic transmission (Miles et al., 1988). Increasing the $\mathrm{Ca}^{2}$ concentration to $10 \mathrm{~mm}$ suppressed polysynaptic transmission enough to prevent epileptiform activity effectively.

Figure 2 illustrates an experiment of this type. Layer Ia afferents were used as the strong pathway and layer Ib intrinsic association fibers as the weak pathway. $\mathrm{Ca}^{2+}$ was elevated throughout this recording. Neither trains to afferents alone nor $5 \mathrm{~Hz}$ weak shocks to association fibers alone produced potentiation of association fiber responses. LTP was produced only when the stimuli were given simultaneously and only when bicuculline was used to block $\mathrm{GABA}_{\mathrm{A}}$-mediated inhibition. The example in the figure shows a potentiation of approximately $50 \%$ above baseline, which was the greatest amount of associative LTP observed with this technique. Induction of associative LTP was seen in 5 of 10 slices with this approach.

Concerns about activation of nonphysiological processes in high $\mathrm{Ca}^{2+}$ led to the development of a second method for blocking $\mathrm{GABA}_{A}$ inhibition without initiating epileptiform activity. Focal, iontophoretic application of bicuculline either from the recording pipette or from a second pipette inserted near the recording site allowed the use of standard medium. Since GA$\mathrm{BA}_{\mathrm{A}}$ blockade occurred only at the recording site and the remainder of the slice was unaffected, epileptiform bursting was avoided, perhaps by keeping the population of disinhibited cells below a critical number required for reverberating positive feedback (Traub and Wong, 1983). Current injection could be used to regulate the amount of bicuculline passing into the slice, although in most experiments diffusion of bicuculline was sufficient to block inhibition without any current. Using this meth-
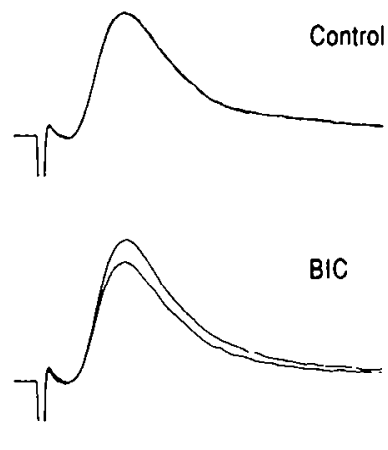

Figure 3. Associative LTP induction after focal application of bicuculline in normal bathing medium. $A$, Potentiation of afferent response by burst stimulation of association fibers: slope of rising phase of field EPSP versus time, baseline response normalized to $100 \%$. $B a r$ denotes period of focal application of bicuculline $(B I C)$ near the recording site. $S$, strong potentiating trains alone; $W$, weak shocks alone; $S+W$, paired stimulation. Test pulses were delivered every $10 \mathrm{sec}$; each point is an average of eight consecutive responses. Averaged response traces (right) are arranged as in Figure 2. $B$, Potentiation of association fiber response by burst stimulation of afferents. Test pulses were delivered every $30 \mathrm{sec}$; each point is an average of four consecutive responses. Calibration: $2 \mathrm{msec}, 1 \mathrm{mV}$. od, robust associative LTP was consistently observed without epileptiform activity.

In the examples shown (Fig. 3), bicuculline was introduced through a second pipette near the recording site. Paired stimulation without bicuculline did not produce LTP, while the same paired stimulation was effective at inducing LTP after insertion of the bicuculline-containing pipette. Control stimuli to afferents alone and to association fibers alone produced no potentiation in the presence of bicuculline, indicating that the LTP observed was associative in nature.

Associative LTP was reliably produced in both directions: afferent responses were potentiated by strong stimulation of association fibers paired with weak stimulation of afferents (Fig. $3 A ; 12$ of 12 slices) and association fiber responses were potentiated by strong stimulation of afferents paired with weak stimulation of association fibers (Fig. $3 B ; 15$ of 16 slices). The magnitude of associative LTP in each pathway was similar to that of homosynaptically induced LTP (Kanter and Haberly, 1990). A potentiation of $10-15 \%$ was typically obtained for the afferent pathway from a single stimulus train, with saturation after multiple trains at $15-25 \%$. A potentiation of $20-40 \%$ was typically obtained for the association fiber pathway from a single train, with saturation at $50-75 \%$. The time course was also similar to that of homosynaptic LTP, with a more rapid onset of potentiation seen in afferent fibers, and an early, decremental phase seen in association fiber potentiation. Bicuculline produced no apparent increase in the magnitude of homosynaptically induced LTP in either pathway.

Given the ability of a $\mathrm{GABA}_{\mathrm{A}}$ antagonist to enable associative LTP induction, we examined whether $\mathrm{GABA}_{\mathrm{B}}$ blockade has a similar effect on plasticity. In the presence of the $\mathrm{GABA}_{\mathrm{B}}$ antagonists phaclofen (two slices) or 2-hydroxysaclofen (two slices), no associative LTP was observed. Associative LTP could sub- 

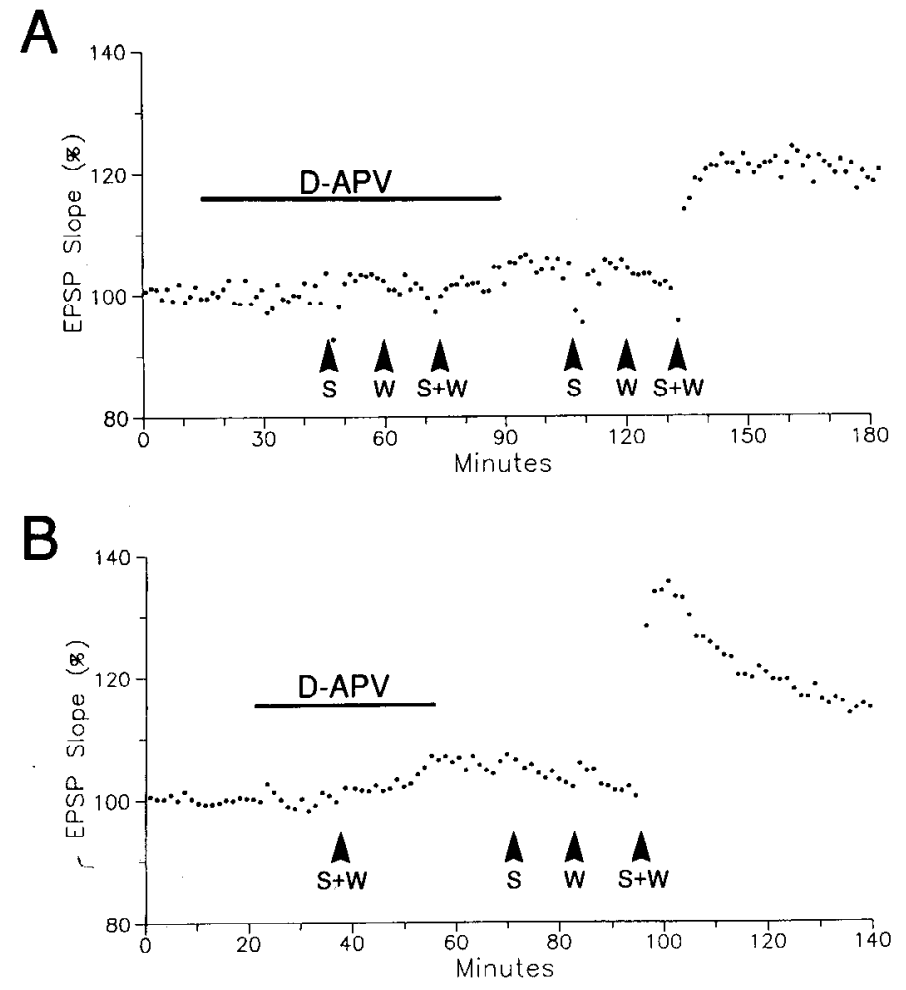

Figure 4. D-APV blocks induction of associative LTP in both pathways. $A$, Potentiation of afferent response by burst stimulation of association fibers: slope of rising phase of field EPSP versus time, baseline response normalized to $100 \%$. Bar denotes period of application of 15 $\mu \mathrm{M}$ D-APV. Bicuculline was introduced focally throughout the experiment by diffusion from the recording pipette. $S$, strong potentiating trains alone; $W$, weak shocks alone; $S+W$, paired stimulation. Test pulses were delivered every $10 \mathrm{sec}$; each point is an average of eight consecutive responses. $B$, Potentiation of association fibcr response by burst stimulation of afferents. Test pulses were delivered every $20 \mathrm{sec}$; each point is an average of four consecutive responses.

sequently be induced in these slices upon introduction of bicuculline. The concentrations of phaclofen $(500 \mu \mathrm{M})$ and 2-hydroxysaclofen $(250 \mu \mathrm{M})$ used were sufficient to block reversibly the intracellularly recorded slow, $\mathrm{K}^{+}$-mediated IPSP in piriform cortex (Hoffman and Haberly, 1989; E. D. Kanter and L. B. Haberly, unpublished observations).

It has previously been demonstrated that the induction of homosynaptic LTP in both afferent and association fiber pathways is dependent on NMDA receptors (Kanter and Haberly, 1990). To determine if associative LTP in these pathways has a similar dependence, the selective NMDA receptor antagonist D-APV was applied in the bathing medium during stimulus trains (Fig. 4). Induction in both directions was blocked by 15 $\mu \mathrm{M}$ D-APV (three slices for each direction), indicating that the associative form of potentiation is also dependent on NMDA receptors.

Figure 5 illustrates the effect of bicuculline on responses during burst stimulation. When four-pulse, $100 \mathrm{~Hz}$ bursts were recorded extracellularly in normal medium, the time course of the field EPSP was rapid enough so that there was no summation of responses. After introduction of bicuculline a slower response component appeared that summated over the burst. This slow component was blocked by $15 \mu \mathrm{M} \mathrm{D}$-APV, suggesting that it is an NMDA receptor-dependent component that is normally suppressed by $\mathrm{GABA}_{\mathrm{A}}$ inhibition.

\section{Discussion}

The present results have demonstrated that associative LTP can occur in both directions between afferent inputs on distal apical dendrites and association fiber inputs on proximal apical dendrites of pyramidal cells in the piriform cortex. Like homosynaptic LTP in the same fiber systems, induction of this associative LTP was dependent on activation of NMDA receptors. However, in contrast to homosynaptic LTP that can be elicited in standard bathing medium, associative LTP was only observed when $\mathrm{GABA}_{\mathrm{A}}$ synaptic transmission was blocked during the potentiating stimulus trains.

\section{Mechanism for modulation of associative LTP by inhibitory processes}

The NMDA dependence and similarity in magnitude and time course suggest that the LTP induced by temporally associated activity in afferent and association fiber systems is equivalent to that evoked in either fiber system alone. An important question is, therefore, why blockade of $\mathrm{GABA}_{\mathrm{A}}$ receptors is required for associative but not homosynaptic induction.

From work on hippocampal cortex (Gustafsson and Wigström, 1986; Kelso et al., 1986; Sastry et al., 1986; Wigström et al., 1986; Gustafsson et al., 1987) it has been postulated that associative LTP of the form observed in the present study occurs when depolarization from the strong stimulus train spreads to the location of synapses activated by the weak stimulus, thereby allowing activation of NMDA receptors that are largely blocked by $\mathrm{Mg}^{2+}$ at resting membrane potential. Consequently, it can be postulated that blockade of $\mathrm{GABA}_{\mathrm{A}}$ transmission increases the level of depolarization attained in the weakly stimulated synaptic zone in two possible ways: by facilitating the electrotonic spread of potential and/or by increasing the level of depolarization achieved in the strongly stimulated zone. The increase in electrotonic spread of EPSPs would be a consequence of blocking the $\mathrm{Cl}^{-}$conductance, thereby increasing the membrane resistance and length constant.

The induction of an NMDA dependent slow component and its buildup during potentiating trains (Fig. 5) is consistent with an increased level of aepolarization in the zone receiving the strong stimulus train. Blockade of the fast, $\mathrm{Cl}^{-}$-mediated IPSP would also be expected to increase the amplitude of the nonNMDA-mediated EPSP component. Amplitudes of concomitant EPSPs would be reduced by this IPSP in spite of its depolarizing polarity in piriform cortex (Scholfield, 1978), since the $\mathrm{Cl}^{-}$equilibrium potential is at a hyperpolarized level with respect to the peak of all but the smallest EPSPs.

Given that the conductance increases associated with GA$\mathrm{BA}_{\mathrm{A}}$ - and $\mathrm{GABA}_{\mathrm{B}}$-mediated IPSPs in piriform cortex are roughly comparable as measured at the cell body, and that the GA$\mathrm{BA}_{\mathrm{B}}$-mediated IPSP is more strongly hyperpolarizing (Tseng and Haberly, 1988), it is surprising that associative LTP in apical dendrites can be induced with $\mathrm{GABA}_{\mathrm{A}}$, but not $\mathrm{GABA}_{\mathrm{B}}$ antagonists. In addition, experiments using local application of GABA agonists or blockers of synaptic transmission such as $\mathrm{Cd}^{2+}$ have shown that a large component of the $\mathrm{GABA}_{\mathrm{A}}$ response is generated at the cell body, while the $\mathrm{GABA}_{\mathrm{B}}$ response is generated predominantly in the dendrites (Newberry and Nicoll, 1985; Tseng and Haberly, 1988).

Several factors could contribute to this finding. First, the experiments on spatial localization of IPSPs do not rule out the presence of a significant $\mathrm{GABA}_{\mathrm{A}}$ component in the dendrites, 

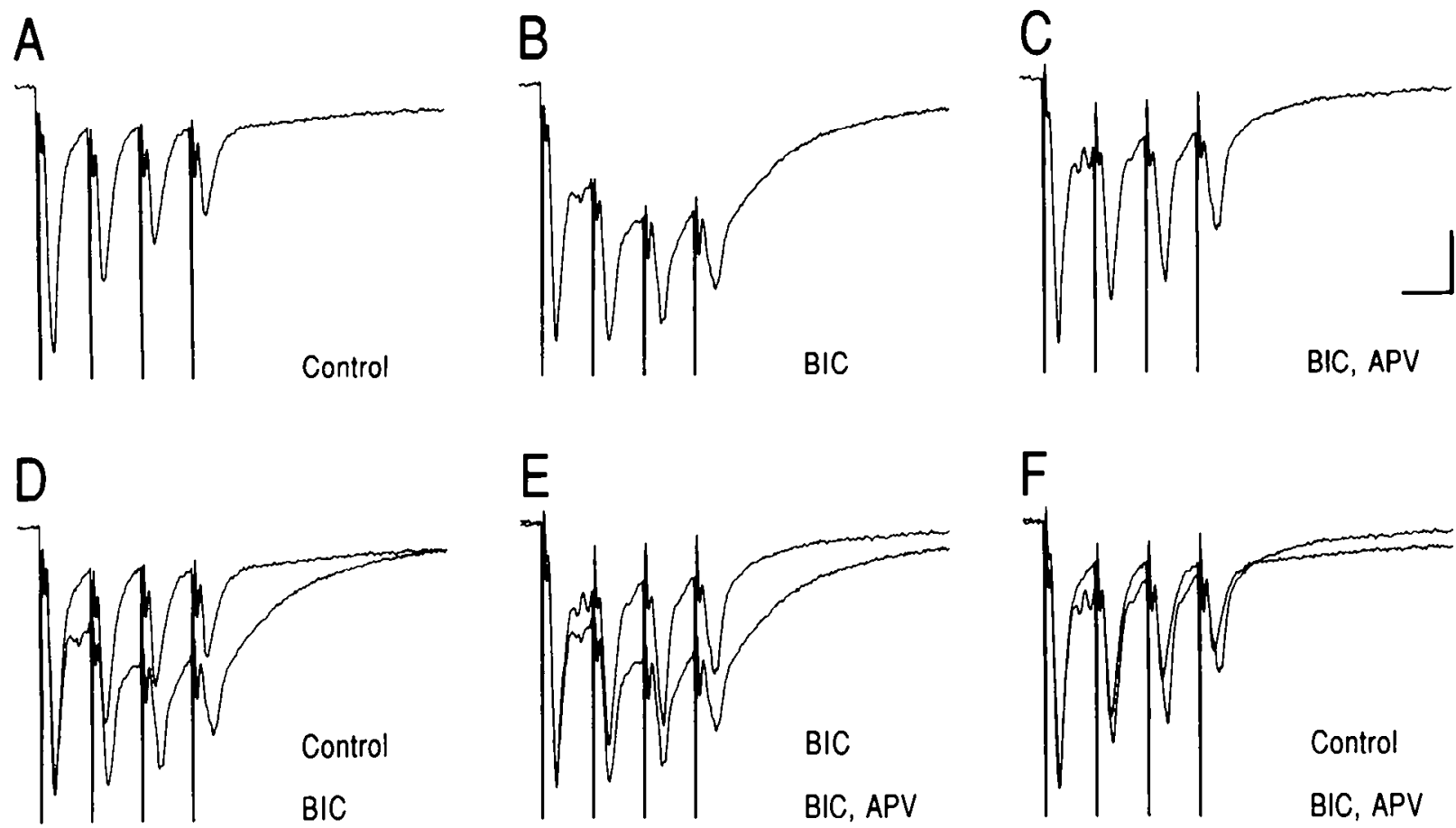

Figure 5. Effect of bicuculline on field potentials during potentiating trains: responses to burst stimulation (four pulses at $100 \mathrm{~Hz}$ ) of association fibers in layer Ib. Shock strength was adjusted to give response amplitudes of $4.0 \mathrm{mV}$ for the initial peak. $A$, Response under control conditions. $B$, Focal application of bicuculline $(B I C)$ resulted in a long-lasting depolarization. $C$, Bicuculline effect was blocked by $15 \mu \mathrm{M} D$-APV. $D$, Superposition of $A$ and $B$. E. Superposition of $B$ and $C$. F, Superposition of $A$ and $C$. Calibration: $10 \mathrm{msec}, 1 \mathrm{mV}$.

since a dendritic component would have been reduced in amplitude by electrotonic spread to the somatic recording site. Second, activation of presynaptic $\mathrm{GABA}_{\mathrm{B}}$ receptors reduces GABA release in hippocampus, leading to decreases in both $\mathrm{GABA}_{A}$ and $\mathrm{GABA}_{\mathrm{B}}$ responses, and by this mechanism facilitates LTP (Davies et al., 1991; Mott and Lewis, 1991). If presynaptic $G_{A B A}$ receptors are also present in piriform cortex, then $\mathrm{GABA}_{B}$ antagonists could increase $\mathrm{GABA}_{A}$-mediated inhibition in addition to blocking the slow IPSP. The increased $\mathrm{GABA}_{\mathrm{A}}$-mediated inhibition could have therefore compensated for the decreased postsynaptic $\mathrm{GABA}_{\mathrm{B}}$ inhibition. Finally, the

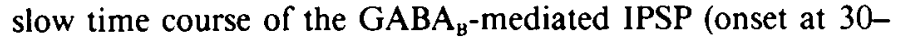
$50 \mathrm{msec}$ and peak at $150-250 \mathrm{msec}$ under present conditions) would preclude a substantial modulatory role during the first burst-weak shock pairing, and fatigue that occurs at a repetition rate of $5 \mathrm{~Hz}$ could have limited its strength during subsequent pairings.

\section{Functional significance}

On the behavioral level, memory storage is modulated according to the "significance" of incoming sensory information. In the LTP model, such regulation of plasticity is necessary to avoid saturation of synapses. Control of inhibition is one possible mechanism whereby modulatory neural inputs could determine whether a synaptic network is in a learning-receptive state. GA$\mathrm{BA}_{\mathrm{A}}$ transmission could serve as a "final common pathway" on which several systems might converge in the regulation of synaptic plasticity.

It is conceivable that levels of inhibition evoked by natural odor stimuli are less than those elicited by the synchronous activation of fibers in vitro, and therefore that disinhibition is not required for the induction of associative LTP in vivo. How- ever, in view of the need for strong convergent excitation to exceed the threshold for LTP induction, it seems reasonable to postulate that disinhibition is required in vivo as well.

In the hippocampus, a variety of neurotransmitter systems have been implicated in the modulation of GABAergic inhibition, including norepinephrine (Andreasen and Lambert, 1991; Doze et al., 1991), 5-HT (Ropert and Guy, 1991), enkephalin (Madison and Nicoll, 1988; Lupica and Dunwiddie, 1991), somatostatin (Scharfman and Schwartzkroin, 1989), and ACh (Pitler and Alger, 1992). Anatomically, physiologically, and pharmacologically distinct subpopulations of GABAergic neurons have been described in piriform cortex (Haberly, 1990; Sheldon and Aghajanian, 1990) that could serve as targets for this modulatory action.

An intriguing possibility is that the segregation of afferent and association fiber inputs to different dendritic regions serves to allow associative plasticity to be modulated by centrifugal pathways that terminate on GABAergic interneurons. In the absence of such segregation, associative LTP would presumably occur without disinhibition. Consistent with this idea is the demonstration that, in the temporodentate pathway from entorhinal cortex to dentate gyrus, associative interactions between crossed and uncrossed projections are dependent on the degree of spatial overlap of synapses (White et al., 1990).

Piriform cortex and hippocampal cortex share simple, orderly structural features that qualify them as model cortical systems. An advantage of piriform cortex over hippocampus is that as a primary sensory cortex, it lends itself well to investigation of the role of synaptic plasticity in memory storage and discriminative processes (Haberly and Bower, 1989). The piriform cortex may therefore be a useful system in which to investigate how synaptic plasticity relates to circuitry and system function. 


\section{References}

Ambros-Ingerson J, Granger R, Lynch G (1990) Simulation of paleocortex performs hierarchical clustering. Science 247:1344-1348.

Andreasen M, Lambert JDC (1991) Noradrenaline receptors participate in the regulation of GABAergic inhibition in area CAl of the rat hippocampus. J Physiol (Lond) 439:649-669.

Barrionuevo G, Brown TH (1983) Associative long-term potentiation in hippocampal slices. Proc Natl Acad Sci USA 80:7347-7351.

Bliss TVP, Lynch MA (1988) Long-term potentiation of synaptic transmission in the hippocampus: properties and mechanisms. In: Long-term potentiation: from biophysics to behavior (Landfield $\mathrm{PW}$, Deadwyler SA, eds), pp 3-72. New York: Liss.

Davies CH, Starkey SJ, Pozza MF, Collingridge GL (1991) GABA autoreceptors regulate the induction of LTP. Nature 349:609-611.

Doze VA, Cohen GA, Madison DV (1991) Synaptic localization of adrenergic disinhibition in the rat hippocampus. Neuron 6:889-900.

Gustafsson B, Wigström H (1986) Hippocampal long-lasting potentiation produced by pairing single volleys and brief conditioning tetani evoked in separate afferents. J Neurosci 6:1575-1582.

Gustafsson B, Wigström H, Abraham WC, Huang Y-Y (1987) Longterm potentiation in the hippocampus using depolarizing current pulses as the conditioning stimulus to single volley synaptic potentials. J Neurosci 7:774-780.

Haberly LB (1985) Neuronal circuitry in olfactory cortex: anatomy and functional implications. Chem Senses 10:219-238.

Haberly LB (1990) Olfactory cortex. In: The synaptic organization of the brain (Shepherd GM, ed), pp 317-345. New York: Oxford.

Haberly LB, Bower JM (1989) Olfactory cortex: model circuit for study of associative memory? Trends Neurosci 12:258-264.

Hoffman WH, Haberly LB (1989) Do changes in synaptic excitation or inhibition underlie generation of long-lasting bursting-induced late EPSPs in piriform cortex? Soc Neurosci Abstr 15:700.

Jung MW, Larson J, Lynch G (1990) Long-term potentiation of monosynaptic EPSPs in rat piriform cortex in vitro. Synapse 6:279-283.

Kanter ED, Haberly LB (1990) NMDA-dependent induction of longterm potentiation in afferent and association fiber systems of piriform cortex in vitro. Brain Res 525:175-179.

Kanter ED, Haberly LB (1991) Associative long-term potentiation in piriform cortex slices requires GABA blockade. Soc Neurosci Abstr 17:386.

Kelso SR, Ganong AH, Brown TH (1986) Hebbian synapses in hippocampus. Proc Natl Acad Sci USA 83:5326-5330.

Ketchum KL, Haberly LB (1991) Fast oscillations and dispersive propagation in olfactory cortex and other cortical areas: a functional hypothesis. In: Olfaction as a model system for computational neuroscience (Davis J, Eichenbaum H, eds), pp 69-100. Cambridge, MA: MIT Press.

Larson J, Wong D, Lynch G (1986) Patterned stimulation at the theta frequency is optimal for the induction of hippocampal long-term potentiation. Brain Res 368:347-350.

Levy WB, Steward O (1979) Synapses as associative memory elements in the hippocampal formation. Brain Res 175:233-245.

Lupica CR, Dunwiddie TV (1991) Differential effects of mu- and deltareceptor selective opioid agonists on feedforward and feedback GABAergic inhibition in hippocampal brain slices. Synapse 8:237-248.

Macrides F, Eichenbaum HB, Forbes WB (1982) Temporal relationship between sniffing and the limbic $\theta$ rhythm during odor discrimination reversal learning. J Neurosci 2:1705-1717.

Madison DV, Nicoll RA (1988) Enkephalin hyperpolarizes interneurones in the rat hippocampus. J Physiol (Lond) 398:123-130.
Madison DV, Malenka RC, Nicoll RA (1991) Mechanisms underlying long-term potentiation of synaptic transmission. Annu Rev Neurosci 14:379-397.

Miles R, Traub RD, Wong RKS (1988) Spread of synchronous firing in longitudinal slices from the $\mathrm{CA} 3$ region of the hippocampus. $J$ Neurophysiol 60:1481-1496.

Mott DD, Lewis DV (1991) Facilitation of the induction of long-term potentiation by $\mathrm{GABA}_{\mathrm{B}}$ receptors. Science 252:1718-1720.

Newberry NR, Nicoll RA (1985) Comparison of the action of baclofen with $\gamma$-aminobutyric acid on rat hippocampal pyramidal cells in vitro. J Physiol (Lond) 360:161-185.

Pitler TA, Alger BE (1992) Cholinergic excitation of GABAergic interneurons in the rat hippocampal slice. J Physiol (Lond) 450:127142.

Price JL (1973) An autoradiographic study of complementary laminar patterns of termination of afferent fibers to the olfactory cortex. J Comp Neurol 150:87-108.

Ropert N, Guy N (1991) Serotonin facilitates GABAergic transmission in the CAl region of rat hippocampus in vitro. J Physiol (Lond) 441: 121-136.

Sastry BR, Goh JW, Auyeung A (1986) Associative induction of posttetanic and long-term potentiation in CAl neurons of rat hippocampus. Science 232:988-990.

Satou M, Mori K, Tazawa, Y, Takagi SF (1982) Two types of postsynaptic inhibition in pyriform cortex of the rabbit: fast and slow inhibitory postsynaptic potentials. J Neurophysiol 48:1142-1156.

Scharfman HE, Schwartzkroin PA (1989) Selective depression of GABA-mediated IPSPs by somatostatin in area CAl of rabbit hippocampal slices. Brain Res 493:205-211.

Scholfield CN (1978) A depolarizing inhibitory potential in neurones of the olfactory cortex. J Physiol (Lond) 275:547-557.

Sheldon PW, Aghajanian GK (1990) Serotonin (5-HT) induces IPSPs in pyramidal layer cells of rat piriform cortex: evidence for the involvement of a 5- $\mathrm{HT}_{2}$-activated interneuron. Brain Res 506:62-69.

Traub RD, Wong RKS (1983) Synchronized burst discharge in disinhibited hippocampal slice. II. Model of cellular mechanism. J Neurophysiol 49:459-471.

Tseng G-F, Haberly LB (1988) Characterization of synaptically mediated fast and slow inhibitory processes in piriform cortex in an in vitro slice preparation. J Neurophysiol 59:1352-1376.

White G, Levy WB, Steward O (1990) Spatial overlap between populations of synapses determines the extent of their associative interaction during the induction of long-term potentiation and depression. J Neurophysiol 64:1186-1198.

Wigström H, Gustafsson B (1983) Facilitated induction of hippocampal long-lasting potentiation during blockade of inhibition. Nature 301:603-604.

Wigström H, Gustafsson B (1985) Facilitation of hippocampal longlasting potentiation by GABA antagonists. Acta Physiol Scand 125: 159-172.

Wigström H, Gustafsson B, Huang Y-Y, Abraham WC (1986) Hippocampal long-lasting potentiation is induced by pairing single afferent volleys with intracellularly injected depolarizing current pulses. Acta Physiol Scand 126:317-319.

Wilson MA, Bower JM (1988) A computer simulation of olfactory cortex with functional implications for storage and retrieval of olfactory information. In: Neural information processing systems (Anderson DZ, ed), pp 114-126. New York: American Institute of Physics. 